\title{
Safe Margin beyond Dens Tips to Ventral Dura in Anterior Odontoid Screw Fixation : Analysis of Three-Dimensional Computed Tomography Scan of Odontoid Process
}

\author{
Min-Jae Sung, MD., ${ }^{1,2}$ Kyoung-Tae Kim, MD., Ph.D., ${ }^{1,2}$ Jeong-Hyun Hwang, MD., Ph.D., ${ }^{1,2}$ Joo-Kyung Sung, MD., Ph.D., ${ }^{1,2}$ \\ Dae-Chul Cho, MD., Ph.D., \\ Department of Neurosurgery, Kyungpook National University Hospital, Daegu, Korea \\ Department of Neurosurgery, ${ }^{2}$ School of Medicine, Kyungpook National University, Daegu, Korea
}

Objective : Anterior odontoid screw fixation is a safe and effective method for the treatment of odontoid fractures. The surgical technique is recommended for perforation of the apical cortex of the dens by the lag screw. However, overpenetration of the apical cortex may lead to potentially serious complications such as damages of adjacent vascular and neural structures. The purpose of this study was to assess the role of three-dimensional computed tomography (CT) scan to evaluate the safe margin beyond dens tip to ventral dura for anterior odontoid screw fixation.

Methods : We retrospectively analyzed the three-dimensional CT scans of the cervical spines in 55 consecutive patients at our trauma center. The patients included 38 males and 17 females aged between 22 and 73 years (mean age \pm standard deviation, $45.8 \pm 14.2$ years). Using sagittal images of 3-dimensional CT scan, the safe margins beyond dens tip to ventral dura as well as the appropriate screw length were measured.

Results : The mean width of the apical dens tip was $9.6 \pm 1.1 \mathrm{~mm}$. The mean lengths from the screw entry point to the apical dens tip and posterior end of dens tip were $39.2 \pm 2.6 \mathrm{~mm}$ and $36.6 \pm 2.4 \mathrm{~mm}$. The safe margin beyond apical dens tip to ventral dura was $7.7 \pm 1.7 \mathrm{~mm}$. However, the safe margin beyond the posterior end of dens tip to ventral dura was decreased to $2.1 \pm 3.2 \mathrm{~mm}$, which was statistically significant $(p<0.01)$. There were no significant differences of safe margins beyond dens tip to ventral dura with patient gender and age.

Conclusion : Extension by several millimeters beyond the dens tip is safe, if the trajectory of anterior odontoid screw is targeted at the apical dens tip. However, if the trajectory of the screw is targeted to the posterior end of dens tip, extension beyond dens tip may lead to damage immediately adjacent to the vental dura mater.

Key Words : Bone screws · Odontoid process · Spinal fractures.

\section{INTRODUCTION}

Anterior odontoid screw fixation is an ideal surgical option to stabilize type II odontoid fractures, because it provides a high union rate without limiting neck motion ${ }^{1,2,4,9,10}$. We have recently reported that a fracture gap of $\geq 2 \mathrm{~mm}$ resulted in a

- Received : February 9, 2018 •Revised : April 2, 2018 •Accepted : April 9, 2018

- Address for reprints : Dae-Chul Cho, M.D., Ph.D.

Department of Neurosurgery, Kyungpook National University Hospital, School of Medicine, Kyungpook National University, 130 Dongdeok-ro, Jung-gu, Daegu 41944, Korea Tel : +82-53-420-5649, Fax : +82-53-423-0504, E-mail : dccho@knu.ac.kr

This is an Open Access article distributed under the terms of the Creative Commons Attribution Non-Commercial License (http://creativecommons.org/licenses/by-nc/4.0) which permits unrestricted non-commercial use, distribution, and reproduction in any medium, provided the original work is properly cited. 
21-fold increase nonunion rates after anterior odontoid screw fixation $^{7)}$. Therefore, in case of type II odontoid fractures, we believe that the fracture gap of odontoid fracture is one of the important risk factors for successful bony union ${ }^{7,14)}$. Although cannulated lag screws or headless compression screws are frequently used to compress and tighten the fracture gap during anterior odontoid screw fixation, it may not be easy to achieve effective reduction ${ }^{7,10,15,16)}$. To enhance the lag effect during inter-fragmentary compression, in general, the recommended surgical technique is believed to perforate the apical dens tip by the screw, and for correct sizing of the implant to obtain bicortical purchase ${ }^{1-3,5,6)}$.

However, the cortical purchase by the cannulated screw may be technically challenging and difficult, because the brain stem is located just beyond the apical cortex of the odontoid process, and any overpenetration of the apical cortex by the screw may damage the vertebral artery and neural tissue $^{2,14,17)}$. To our knowledge, there is no previous study analyzing the distance from the apical dens tip to the adjacent neural structure.

The purpose of this study was to analyze the three-dimensional computed tomography (CT) scans to evaluate the distance from the apical dens tip to the adjacent neural structure through the trajectory of the anterior odontoid screw, and demonstrate the safe margin from the dens tip to the adjacent neural structures during anterior odontoid screw fixation.

\section{MATERIALS AND METHODS}

We retrospectively analyzed the three-dimensional CT scans of the cervical spine in 55 consecutive patients, who were scanned at our trauma center after traffic accidents. None of the patients sustained any fracture of the cervical spine. After appropriate Institutional Review Board approval (2016-07-003), we retrospectively reviewed and analyzed the patient medical charts and their sagittal reconstructions of the 3-dimensional CT scans in order to measure the width of the apical dens tip, length for anterior odontoid screw, and safe margin beyond dens tip to ventral dura.

The entry point for the anterior odontoid screw was marked at the anterior-inferior portion of the body of axis on the sagittal CT images. The apex of dens tip and the posterior end of the dens tip were marked as well (Fig. 1). The width of apical dens tip was measured horizontally in the middle of anterior arch of $\mathrm{Cl}$ (Fig. 2A). The mean lengths from the entry point to the apex of dens tip, and the mean lengths from the entry point to the posterior end of dens tip were measured, respectively (Fig. 2B). The safe margin was defined as the distance from the dens tip to the adjacent dura mater. Safe margin beyond the apical dens tip to ventral dura, and safe margin beyond the posterior end of dens tip to ventral dura were measured, respectively (Fig. 3). All the parameters were measured using the automated measuring tool on the PACS system (PiViewSTAR 5.0; INFINITT, Seoul, Korea). All values were measured in triplicate and averaged.

\section{Statistical analysis}

All statistical analyses were performed using Statistical Package for the Social Sciences software version 18 (SPSS Inc., Chicago, IL, USA). All data were espressed as mean \pm standard deviations. Significant differences in safe margin between the apex of dens tip and posterior end of dens tip were determined using the independent t-test. The threshold for statistical significance was set at $p<0.05$.

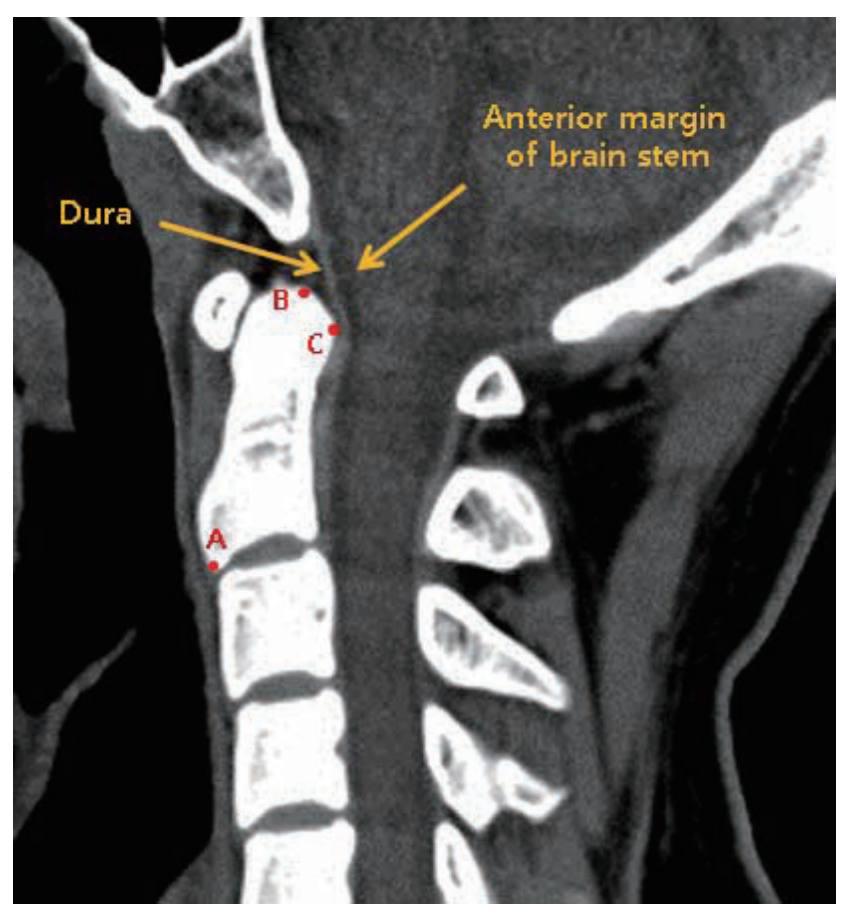

Fig. 1. Sagittal reconstructed computed tomography images showing screw entry point $A$ and the point of dens tip ( $B$ is the apical dens tip and $C$ is the posterior end of dens tip). Arrows point out dura mater and brain stem just beyond dens tip. 

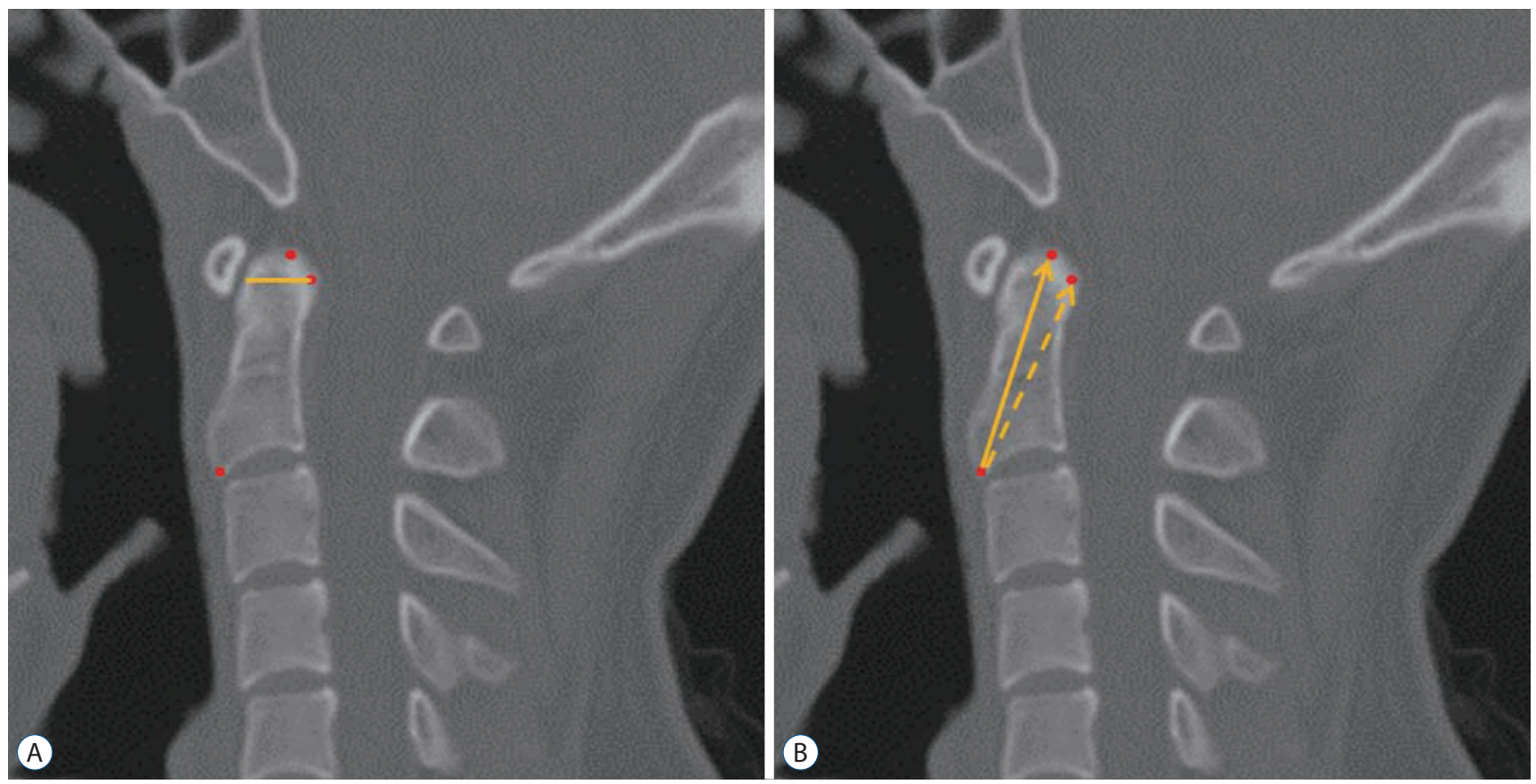

Fig. 2. Showing how to measure the width of apical dens tip (A), and screw length to dens tip (B). Solid arrow means the length from the screw entry point to the apical dens tip, and dotted arrow means the length to the posterior end of dens tip.

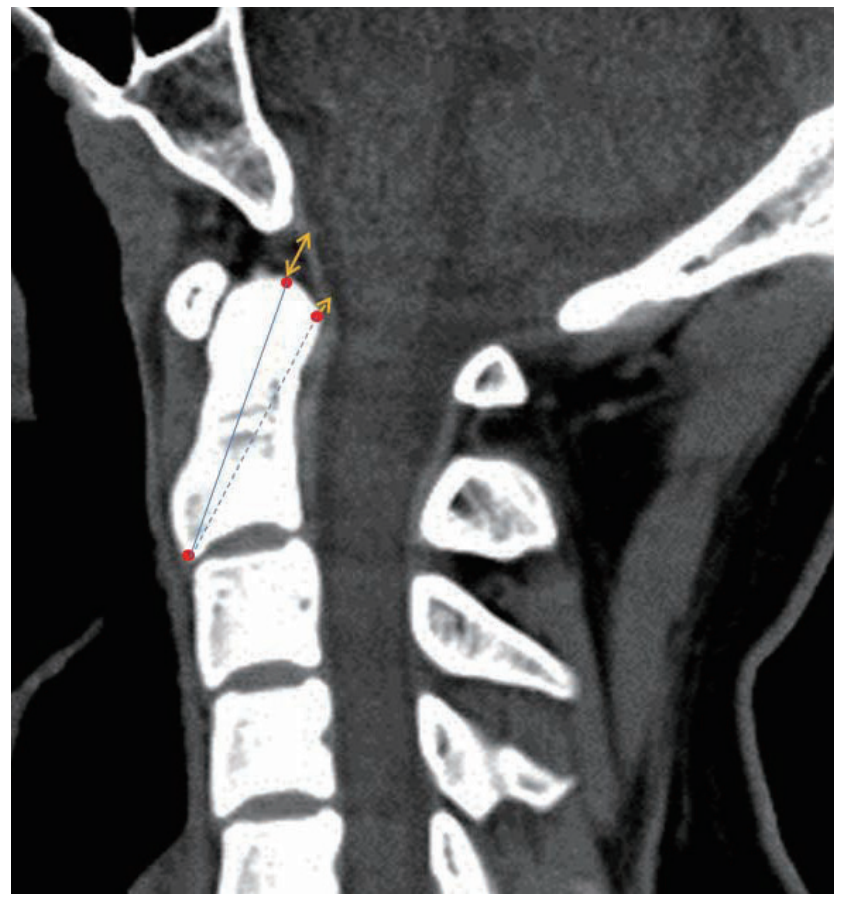

Fig. 3. Showing how to measure safe margin from dens to adjacent dura.

For analysis, patients were dichotomized by gender (male and female), and age (younger than 60 years and those 60 years or older).

\section{RESULTS}

There were 38 male and 17 female patients with ages ranging from 22 to 73 years (mean age \pm standard deviation, $45.8 \pm$ 14.2 years). The mean width of the apical dens tip was $9.6 \pm 1.1$ $\mathrm{mm}$. The mean lengths from the screw entry point to the apical dens tip and posterior end of dens tip were $39.2 \pm 2.6 \mathrm{~mm}$ and $36.6 \pm 2.4 \mathrm{~mm}$. Safe margin beyond the apex of dens tip to ventral dura was $7.7 \pm 1.7 \mathrm{~mm}$. However, the safe margin beyond the posterior end of dens tip to ventral dura was decreased to $2.1 \pm 3.2 \mathrm{~mm}$, which was statistically different $(p<0.01)$. There were no statistical differences in safe margins beyond dens tip to ventral dura between patients' gender and age (Table 1).

\section{DISCUSSION}

Although the risk factors for nonunion after anterior odontoid screw fixation were disputed, the fracture gap was generally considered as one of the significant risk factors ${ }^{7,810-13)}$. In our previous study, a fracture gap $\geq 2 \mathrm{~mm}$ was found to be significantly associated with fusion failure after anterior odontoid screw fixation, therefore we also believe the gap of odon- 
Table 1. Safe margins between gender and age groups

\begin{tabular}{lcc}
\hline & Safe margin from apical dens tip $(\mathrm{mm})$ & Safe margin from post. ends of dens tip $(\mathrm{mm})$ \\
\hline Gender & & $1.9 \pm 0.4$ \\
Male & $7.5 \pm 1.5$ & $2.2 \pm 0.6$ \\
Female & $7.5 \pm 2.0$ & $2.0 \pm 0.5$ \\
Age & & $2.2 \pm 0.7$ \\
Young ( $<60$ years $)$ & $7.8 \pm 1.5$ & $7.6 \pm 1.8$ \\
Old $(>60$ years $)$ & & \\
\hline
\end{tabular}

Values are presented as mean \pm standard deviation

toid fracture is one of the important risk factors for successful bony union ${ }^{7,14}$. Therefore if the surgical technique can reduce the fracture gap, we can achieve higher rates of bone fusion after the operation.

From an orthopedic perspective, inter-fragmentary compression and stable fixation are essential for successful bone fusion, and the pressure at the fractured edges enhances fracture healing in a predictable manner ${ }^{1,5,7,8,13)}$. Therefore, appropriate instrumentation and surgical techniques are needed for the reduction of fracture gap during anterior odontoid screw fixation.

In general, cannulated lag screws or headless Herbert screws are usually used to compress and tighten the fracture gap during anterior odontoid screw fixation ${ }^{7,10,14,16)}$. Theoretically, after the lag screw or headless Herbert screw crosses the fracture line, the threads engage the fragment and the lag effect of the screw reduces the fracture gap. Further tightening of the screw increases the strength of the pull force of the fractured piece in a caudal direction, increasing inter-fragmentary compression, which results in enhanced fracture healing ${ }^{1,4,7,8,10,11)}$. Penetration of the apical dens by the screws is recommended for the sufficient reduction of fracture gap following the lag effect $^{1,2)}$. We totally agreed with the importance of bicortical purchase by the screw.

In our recent biomechanical study, we reported that interfragmentary compression pressures of the Herbert screw were significantly increased when the screw tip penetrated the opposite dens. Our findings support the generally recommended surgical technique, and penetration of the apical dens tip with the screw is essential to facilitate the maximal reduction of the fracture gap during anterior odontoid screw fixation ${ }^{14)}$.

Accurate screw length is essential for anterior odontoid screw fixation. Short screws prevent penetration into the odontoid tip, and cannot pull the fractured odotoid fragment for inter-fragmentary compression. In our study, the mean screw lengths from the screw entry point to the apical dens tip and the posterior end of dens tip were $39.2 \pm 2.6 \mathrm{~mm}$ and $36.6 \pm$ $2.4 \mathrm{~mm}$, respectively, which were consistent with previous study ${ }^{17)}$. These values represent the real screw lengths for anterior odontoid screw fixation, measured as the line through the real screw entry point (anterior-inferior point of the body of axis) to the odontoid tip. Therefore, screws measuring several millimeters longer than the real screw length must be used for the penetration of the odontoid tip by the screw.

However, the cortical purchase by the screw may be technically challenging and stressful to the surgeon, because the brain stem is located slightly beyond the apical cortex of dens, and therefore, over-penetration of the apical cortex by the screw, as well as K-wire or tapping of pilot hole, may damage to the adjacent neurovascular structure. In our previous study, despite all our efforts for penetration of apical dens tip by the Herbert screw, we achieved cortical purchase by the screw in only 16 out of 37 patients (unpublished data). The result was attributed to the fear of damaging the dura immediately beyond the apical dens tip during the anterior odontoid screw fixation. Therefore, preoperatively, it is important to determine the proximity of the apical dens tip to adjacent dura.

The distance from the apical dens tip to the adjacent neural structure has not been reported previously. In the present study, the width of the apical dens tip was sufficiently wide (mean length $9.6 \pm 1.1 \mathrm{~mm}$ ), and the screw was targeted at two different target points of dens tip by the screw trajectory : apical dens tip and posterior end of dens tip. The distance from the apical dens tip to the ventral dura was $7.7 \pm 1.7 \mathrm{~mm}$, suggesting that the safe margin was relatively wide, if the screw trajectory was aimed at the apical dens tip. However, if the screw trajectory is aimed at the posterior end of the dens tip, the safe margin beyond the posterior end of the dens tip to ventral dura 
was decreased to $2.1 \pm 3.2 \mathrm{~mm}$, which suggested that the screw trajectory had a relatively higher risk of dural injury.

The study limitations are as follows. First, we analyzed the safe margin only in patients without odontoid fracture. In the case of odontoid fracture, the real safe margin from apical dens tip to ventral dura can be altered by the fracture displacement and fracture gap. But in the case of odontoid fracture with severe displacement or wide fractured gap, preoperative reduction by proper surgical position is essential for anterior odontoid screw fixation. So we thought that measurement of safe margin in the patient with no fracture is meaningful. However, fracture displacement and fracture gap of odontoid fractures as well as, surgical position of the patient during operation can influence the measurement of the real screw length and safe margin. As mentioned before, the correct size of screw length is also important for the penetration of dens tip by the screw. Second, because the dura is filled with cerebrospinal fluid, brain and vessels do not contact each other directly. Thus the distance from dens tip to the ventral dura cannot determine the real risk of adjacent neurovascular structures. However, our findings highlight the proximity of apical dens tip to the adjacent dura, and safe margin may be tailored according to morphology of fracture.

\section{CONCLUSION}

If the trajectory of anterior odontoid screw is targeted at the apical dens tip, it is safe to extend beyond dens tip by several millimeters. However, if the trajectory of the screw is targeted to the posterior end of the dens tip, extension beyond dens tip may damage the area immediately adjacent to the ventral dura mater.

\section{CONFLICTS OF INTEREST}

No potential conflict of interest relevant to this article was reported.

\section{INFORMED CONSENT}

Informed consent was obtained from all individual partici- pants included in this study.

\section{- Acknowledgements}

The study was funded by AOSpine Korea Research Grant 2016 (project code: $\operatorname{AOSKR}(\mathrm{R}) 2016-11)$.

\section{References}

1. Andersson S, Rodrigues $M$, Olerud C : Odontoid fractures: high complication rate associated with anterior screw fixation in the elderly. Eur Spine J 9 : 56-59, 2000

2. Apfelbaum RI, Lonser RR, Veres R, Casey A : Direct anterior screw fixation for recent and remote odontoid fractures. J Neurosurg 93(2 Suppl) : 227-236, 2000

3. Assari S, Darvish K, llyas AM : Biomechanical analysis of second-generation headless compression screws. Injury 43 : 1159-1165, 2012

4. Börm W, Kast E, Richter HP, Mohr K : Anterior screw fixation in type II odontoid fractures: is there a difference in outcome between age groups? Neurosurgery 52 : 1089-1092; discussion 1092-1094, 2003

5. Chang KW, Liu YW, Cheng PG, Chang L, Suen KL, Chung WL, et al. : One Herbert double-threaded compression screw fixation of displaced type II odontoid fractures. J Spinal Disord 7 : 62-69, 1994

6. Chi YL, Wang XY, Xu HZ, Lin Y, Huang QS, Mao FM, et al. : Management of odontoid fractures with percutaneous anterior odontoid screw fixation. Eur Spine J 16 : 1157-1164, 2007

7. Cho DC, Sung JK : Analysis of risk factors associated with fusion failure after anterior odontoid screw fixation. Spine (Phila Pa 1976) 37 : 30 34, 2012

8. Fountas KN, Kapsalaki EZ, Karampelas I, Feltes CH, Dimopoulos VG, Machinis TG, et al. : Results of long-term follow-up in patients undergoing anterior screw fixation for type II and rostral type III odontoid fractures. Spine (Phila Pa 1976) $30: 661-669,2005$

9. Frangen TM, Zilkens $C$, Muhr $G$, Schinkel $C$ : Odontoid fractures in the elderly: dorsal $\mathrm{C} 1 / \mathrm{C} 2$ fusion is superior to halo-vest immobilization. J Trauma 63 : 83-89, 2007

10. Grauer JN, Shafi B, Hilibrand AS, Harrop JS, Kwon BK, Beiner JM, et al. : Proposal of a modified, treatment-oriented classification of odontoid fractures. Spine J 5 : 123-129, 2005

11. Herbert TJ, Fisher WE : Management of the fractured scaphoid using a new bone screw. J Bone Joint Surg Br 66 : 114-123, 1984

12. Koivikko MP, Kiuru MJ, Koskinen SK, Myllynen P, Santavirta S, Kivisaari $\mathrm{L}$ : Factors associated with nonunion in conservatively-treated type-॥ fractures of the odontoid process. J Bone Joint Surg Br 86 : 11461151, 2004

13. Müller EJ, Wick M, Russe 0 , Muhr $G$ : Management of odontoid fractures in the elderly. Eur Spine J 8 : 360-365, 1999

14. Park JW, Kim KT, Sung JK, Park SH, Seong KW, Cho DC : Biomechanical comparison of inter-fragmentary compression pressures: lag screw 
versus herbert screw for anterior odontoid screw fixation. J Korean Neurosurg Soc 60 : 498-503, 2017

15. Platzer $P$, Thalhammer $G$, Oberleitner $G$, Schuster R, Vécsei V, Gaebler C : Surgical treatment of dens fractures in elderly patients. J Bone Joint Surg Am 89 : 1716-1722, 2007

16. Platzer $P$, Thalhammer $G$, Ostermann $R$, Wieland T, Vécsei V, Gaebler C : An- terior screw fixation of odontoid fracture comparing younger and elderly patients. Spine (Phila Pa 1976) 32 : 1714-1720, 2007

17. Tun K, Kaptanoglu E, Cemil B, Yorubulut M, Karahan ST, Tekdemir I : Anatomical study of axis for odontoid screw thickness, length, and angle. Eur Spine J 18 : 271-275, 2009 